\title{
Bone marrow transplantation for mucopolysaccharidosis type I: experience of two British centres
}

\author{
A Vellodi, E P Young, A Cooper, J E Wraith, B Winchester, C Meaney, U Ramaswami,
} A Will

\begin{abstract}
Bone marrow transplantation was carried out on 38 patients with mucopolysaccharidosis type I over a period of 15 years. The donor was an HLA identical relative in $\mathbf{1 0}$ cases, an HLA non-identical relative in $\mathbf{1 6}$ cases, and an HLA identical unrelated volunteer donor in 12 cases. Ten patients received a second transplant. One patient received three transplants. Thirteen engrafted patients have survived five years or more. Most patients have shown an arrest or slowing down of psychomotor regression. However, dysostosis multiplex has progressed. Careful selection of patients may be necessary to ensure optimum results.

(Arch Dis Child 1997;76:92-99)
\end{abstract}

Keywords: mucopolysaccharidosis type I; bone marrow transplantation.

Medical Unit, Institute of Child Health, 30 Guilford Street, London WC1N 1EH A Vellodi

U Ramaswami

Division of

Biochemistry and

Genetics, Institute of

Child Health, London

E P Young

B Winchester

C Meaney

Willink Biochemical Genetics Unit, Royal Manchester Children's

Hospital

A Cooper

J E Wraith

Bone Marrow

Transplant Unit, Royal

Manchester Children's

Hospital

A Will

Correspondence to:

Dr Vellodi.

Accepted 24 July 1996

Mucopolysaccharidosis type I (MPS-I) is an inherited disorder of metabolism, characterised biochemically by a deficiency of the lysosomal enzyme $\alpha$-L-iduronidase, with the consequent accumulation of the glycosaminoglycans (GAGs) dermatan sulphate and heparan sulphate. Clinically, there is progressive multisystem involvement including degenerative joint disease, and in the more severely affected patients, mental retardation and cardiomyopathy, leading to progressive disability and death. ${ }^{1}$ Bone marrow transplantation (BMT) has been shown to slow down or reverse some of the features of this disease, ${ }^{23}$ but not others. ${ }^{4}$

We present the results of allogeneic bone marrow transplantation for MPS-I at two British centres. The series includes the first patients to have undergone BMT for this condition anywhere.

\section{Patients and methods}

The transplants were performed at the Westminster Children's Hospital, London and the Royal Manchester Children's Hospital. From
1980 to 1995,38 patients (Westminster 27, Manchester 11) with MPS-I underwent a total of 49 allogeneic transplants. The mean age at the time of the first transplant was 19.6 months (6-36 months). There were 19 boys and 19 girls. Most patients presented with typical features of MPS-I, that is stiff joints, dysmorphic facies, and developmental delay. There were two exceptions. One patient presented with corneal clouding and glaucoma, and it was felt that she had a relatively mild phenotype. The other presented at the age of 6 months with congestive cardiac failure, and was found to have a cardiomyopathy. In all cases, the diagnosis of MPS-I was confirmed by assay of leucocyte or fibroblast $\alpha$-L-iduronidase activity.

DONOR DETAILS

The donor was an HLA identical relative in 10 cases (eight sibling, one cousin, one parent), an HLA non-identical relative (at least one antigen mismatch) in 16 cases, and an unrelated donor in 12 cases.

PATIENT DETAILS
TRANSPLANT DETAILS

Most patients received busulphan and cyclophosphamide conditioning for their first transplant (table 1). The early Westminster patients received a lower dose of busulphan, and most received a slightly higher dose of cyclophosphamide. One patient received total nodal irradiation and cyclophosphamide. Prophylaxis against graft-versus-host disease was with cyclosporin, methotrexate, and T cell depletion in varying combinations. All Westminster patients received selective gut decontamination with non-absorbable antibiotics (colistin, neomycin). Sixteen patients were nursed in standard protective isolation; the rest in either laminar flow patient isolators with high efficiency particulate air (HEPA) filtered air (Westminster) or a purpose built HEPA filtered unit (Manchester).

PSYCHOLOGICAL ASSESSMENT

Between five months and a few days before BMT, all patients were assessed using the Ruth Griffiths' mental development scales (GMDS). After transplant, assessment was carried out 
Table 1 Conditioning regimen for first transplant

\begin{tabular}{|c|c|c|c|c|c|}
\hline \multicolumn{3}{|l|}{ Manchester } & \multicolumn{3}{|c|}{ Westminster Children's Hospital } \\
\hline Drug & Dose & No of patients & Drug & Dose & No of patients * \\
\hline \multirow[t]{5}{*}{ Cyclophosphamide } & $\begin{array}{l}16 \mathrm{mg} / \mathrm{kg} \\
200 \mathrm{mg} / \mathrm{kg}\end{array}$ & 11 & $\begin{array}{l}\text { Busulphan } \\
\text { Cyclophosphamide } \\
\text { Busulphan }\end{array}$ & $\begin{array}{l}320 \mathrm{mg} / \mathrm{m}^{2} \text { not }<16 \mathrm{mg} / \mathrm{kg} \\
8 \mathrm{~g} / \mathrm{m}^{2} \text { not }>300 \mathrm{mg} / \mathrm{kg} \\
320 \mathrm{mg} / \mathrm{m}^{2} \text { not }<16 \mathrm{mg} / \mathrm{kg}\end{array}$ & 21 \\
\hline & & & $\begin{array}{l}\text { Cyclophosphamide } \\
\text { Busulphan }\end{array}$ & $\begin{array}{l}200 \mathrm{mg} / \mathrm{kg} \\
8 \mathrm{mg} / \mathrm{kg}\end{array}$ & 1 \\
\hline & & & $\begin{array}{l}\text { Cyclophosphamide } \\
\text { Busulphan }\end{array}$ & $\begin{array}{l}3 \mathrm{~g} / \mathrm{m}^{2} \\
8 \mathrm{mg} / \mathrm{kg}\end{array}$ & 1 \\
\hline & & & $\begin{array}{l}\text { Cyclophosphamide } \\
\text { Busulphan }\end{array}$ & $\begin{array}{l}8 \mathrm{~g} / \mathrm{m}^{2} \text { not }>300 \mathrm{mg} / \mathrm{kg} \\
16 \mathrm{mg} / \mathrm{kg}\end{array}$ & 2 \\
\hline & & & $\begin{array}{l}\text { Cyclophosphamide } \\
\text { TLI }\end{array}$ & $\begin{array}{l}200 \mathrm{mg} / \mathrm{kg} \\
200 \mathrm{cGy} / \text { day } \times 6 \text { days }\end{array}$ & 1 \\
\hline
\end{tabular}

^ Details not available in one patient. All doses expressed as total dose over four days.

TLI = total lymphoid irradiation

every six to 24 months. One child (patient 7) has not been assessed for over four years owing to behavioural difficulties, that is extreme impulsivity and hyperactivity (see discussion) which made formal testing impossible. The following methods were used according to the developmental level of each child.

\section{GMDS}

These scales give a general quotient (GQ). They were standardised in the 1950s, however children's mental development has accelerated over the past 40 years by about 0.38 points per annum, ${ }^{5}$ and the GQs obtained by reference to these scales' norms are very likely to be an overestimate of the children's 'true' GQs of between 9 and 15 points, depending on the date of testing. Suggested 'corrected' GQs are given in parentheses in table 2 .

British ability scales (BAS)

These scales give an intelligence quotient (IQ). They were standardised in 1976, and for the reasons mentioned previously, reference to these scales' norm is likely to be an overestimate of the children's ability level by about 7 points. Suggested 'corrected' figures are given in parentheses in table 2 .

Wechsler intelligence scales for children (WISC) The third UK edition of these scales was used ${ }^{6}$; these scales give an IQ.

MONITORING OF ENGRAFTMENT

Engraftment was monitored using enzyme analysis, karyotype differences (where appro- priate) and, more recently, restriction fragment length polymorphism/in situ hybridisation studies.

\section{GENOTYPING}

A correlation between genotype and phenotype has been described in MPS-I. ${ }^{7}$ This information has been used to assess outcome after BMT for patients 1,2 , and $5 .^{8}$ Accordingly, genotyping was carried out on the remainder of the patients in this study.

DNA PREPARATION

Genomic DNA was extracted from leucocytes obtained before BMT from two patients ( 7 and 10 ), from the parents of patient 3 and from fibroblasts, cultured post-BMT, from patients 4,8 , and 9 by an ammonium acetate salting out procedure as described by Miller et $a l,{ }^{9}$ or by boiling in sodium hydroxide. No DNA was available from patient 6 .

DETECTION OF THE Q70X AND w402X MUTATIONS OF THE $\alpha$-L-IDURONIDASE GENE (IDUA)

In London, the Q70X and W402X mutations were detected by amplification using the polymerase chain reaction (PCR) of exons 2 and 9 respectively, followed by restriction digestion. In Manchester, the mutations were detected by the amplification refractory mutation system (ARMS; manuscript in preparation).

The oligonucleotide primers used for the detection of the Q70X mutation were ID-21 5'-CGCTGCCAGCCATGCTGAGGCTCG

Table 2 Psychometric evaluation before and after BMT. A comparison of pre-BMT and most recent results of the psychometric evaluation of 10 children with MPS-I

\begin{tabular}{|c|c|c|c|c|c|c|c|c|c|}
\hline \multirow[b]{2}{*}{$\begin{array}{l}\text { Patient } \\
\text { No }\end{array}$} & \multicolumn{4}{|c|}{ Pre-BMT results } & \multicolumn{4}{|c|}{ Most recent results } & \multirow[b]{2}{*}{ Discrepancy in $S D$} \\
\hline & $\begin{array}{l}\text { Age } \\
\text { (years) }\end{array}$ & Test & $G Q$ & $S D^{\star}$ & $\begin{array}{l}\text { Age } \\
\text { (years) }\end{array}$ & Test & $G Q / I Q$ & $S D^{\star}$ & \\
\hline $1+$ & 0.7 & GMDS & $77(68)$ & $-1.5(-2.1)$ & 15.7 & BAS & $77(70)$ & $-1.5(-2.0)$ & $< \pm 1.0(< \pm 1.0)$ \\
\hline 2 & 1.2 & GMDS & $76(67)$ & $-1.6(-2.2)$ & 15.5 & BAS & $122(115)$ & $+1.5(+1.0)$ & $+3.7(+3.2)$ \\
\hline $3+$ & 1.9 & GMDS & $82(72)$ & $-1.0(-1.8)$ & 16.2 & WISC & $<50$ & $>3.30$ & $>-2.3(-1.5)$ \\
\hline 4 & 2.0 & GMDS & $70(63)$ & $-2.0(-2.6)$ & 11.1 & BAS & $82(75)$ & $-1.2(-1.6)$ & $< \pm 1.0(< \pm 1.0)$ \\
\hline 5 & 1.0 & GMDS & $118(107)$ & $+1.2(+0.5)$ & 13.5 & WISC & 68 & -2.1 & $-3.3(-2.6)$ \\
\hline $6 \ddagger$ & 2.2 & GMDS & $74(63)$ & $-1.8(-2.5)$ & 13.8 & GMDS & $16(1)$ & $-5.6(-6.6)$ & $-3.8(-4.1)$ \\
\hline $7 \dagger$ & 2.8 & GMDS & $48(36)$ & $-3.5(-4.2)$ & 5.2 & GMDS & $48(35)$ & $-3.5(-4.3)$ & $< \pm 1.0(< \pm 1.0)$ \\
\hline $8 \dagger$ & 0.4 & GMDS & $79(67)$ & $-1.4(-2.2)$ & 8.4 & BAS & $88(81)$ & $-0.8(-1.3)$ & $< \pm 1.0 \quad(< \pm 1.0)$ \\
\hline 9 & 1.7 & GMDS & $67(55)$ & $-2.2(-3.0)$ & 8.3 & BAS & $<62(<55)$ & $>-2.5(-3.0)$ & $< \pm 1.0 \quad(< \pm 1.0)$ \\
\hline 10 & 0.8 & GMDS & $89(76)$ & $-0.8(-1.6)$ & 5.7 & GMDS & $65(50)$ & $-2.4(-3.4)$ & $-1.6(-1.8)$ \\
\hline
\end{tabular}

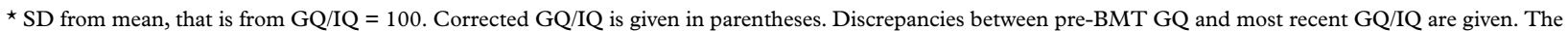
pre-BMT ages refer to age at testing, not at BMT.

† These four children underwent BMT twice. The age at testing pre-BMT is the age before second BMT.

$\ddagger$ GMDS was used in this 13.8 year old child post-BMT, although the GMDS is only standardised for children up to the age of 8 . 
Table 3 Cause of death $(n=17)$

\begin{tabular}{ll}
\hline Graft-versus-host disease & 7 \\
Infection & 2 \\
Cytomegalovirus pneumonitis & 1 \\
Pulmonary haemorrhage & 1 \\
Obliterative bronchiolitis & 1 \\
Acute respiratory failure & 1 \\
Intracerebral haemorrhage & 1 \\
Pneumococcal septicaemia & 1 \\
Adenovirus pneumonitis & 1 \\
Original disease & 1 \\
\hline
\end{tabular}

$-3^{\prime}$ and ID-22 5'-ACACAGGGATGCTCAC GGGTGACC-3'. For the detection of the W402X mutation, the primers were as described by Moscowitz et al. ${ }^{10}$

PCR was performed in a total volume of 50 $\mu \mathrm{l}$ containing $0.1-2 \mu \mathrm{g}$ genomic DNA, $200 \mu \mathrm{M}$ d-nucleoside triphosphates, $1.5 \mathrm{mM}$ magnesium chloride $\left(\mathrm{MgCl}_{2}\right), 16 \mathrm{mM}$ ammonium sulphate, $67 \mathrm{mM}$ Tris-hydrochloric acid $(\mathrm{HCl})$ ( $\mathrm{pH} 8.8$ ), $0.01 \%$ Tween-20, and 20 pmoles of each primer; $4 \%$ dimethyl sulphoxide was added to the PCR reaction, for detection of W402X. After initial denaturation for five minutes at $94^{\circ} \mathrm{C}, 1.1 \mathrm{U}$ of Taqpolymerase (Bioline) was added (hot start method). This was followed by 30 or 35 cycles of one minute denaturation at $94^{\circ} \mathrm{C}$, one minute annealing at $62^{\circ} \mathrm{C}$, and elongation at $72^{\circ} \mathrm{C}$ for one minute for the W402X and Q70X mutations, respectively.

The Q70X mutation can be detected by restriction enzyme digestion because it abolishes a Sau96I restriction site in exon 2 of the IDUA gene. An aliquot of $5 \mu l$ of the PCR product was digested in $40 \mu \mathrm{l}$ reaction mixture using $1 \mu \mathrm{l}$ Sau96I (5U) and $4 \mu$ digestion buffer (10 mM Tris- $\mathrm{HCl}, \mathrm{pH} 7.9,50 \mathrm{mM}$ sodium chloride, $10 \mathrm{mM} \mathrm{MgCl}$, and $1 \mathrm{mM}$ dithiothreitol final concentrations) at $37^{\circ} \mathrm{C}$ for two hours. The products were analysed by electrophoresis in agarose gel (3\% w/v). Digestion of the $470 \mathrm{bp}$ PCR product yields fragments of $310 \mathrm{bp}, 102 \mathrm{bp}$, and $58 \mathrm{bp}$ in normal sequences, but of $310 \mathrm{bp}$ and $160 \mathrm{bp}$ in mutated sequences.

Detection of the W402X mutation was as described by Moscowitz et al. ${ }^{10}$ The A75T mutation found in patient 2 was determined and reported by Clarke et al. ${ }^{11}$

In Manchester, engraftment is monitored by analysis of the variable number of tandem repeats (VNTR), as this is informative in patients with unknown mutations. VNTR analysed are APO-B ${ }^{12}{ }^{13}$ and COL2A $1 .{ }^{14}$

Table 4 Age at BMT and genotype of surviving engrafted patients

\begin{tabular}{llllll}
\hline Patient No & Sex & $\begin{array}{l}\text { Age at first } \\
\text { BMT (years) }\end{array}$ & $\begin{array}{l}\text { Age at second } \\
\text { BMT (years) }\end{array}$ & $\begin{array}{l}\text { Present age } \\
\text { (years) }\end{array}$ & Genotype \\
\hline 1 & $\mathrm{M}$ & 0.8 & 0.9 & 16.2 & W402X/W402X \\
2 & $\mathrm{M}$ & 1.4 & & 15.8 & A75T/A75T \\
3 & $\mathrm{~F}$ & 2.3 & 2.4 & 16.5 & W402X/Q70X \\
4 & $\mathrm{~F}$ & 2.0 & & 15.4 & W402X/Q70X \\
5 & $\mathrm{~F}$ & 1.3 & & 14.1 & W402X/W402X \\
6 & $\mathrm{M}$ & 2.3 & 3.2 & 14.1 & Not done \\
7 & $\mathrm{M}$ & 1.3 & 1.4 & 10.1 & W402X//W402X \\
8 & $\mathrm{~F}$ & 0.4 & & 8.7 & W402X/? \\
9 & $\mathrm{~F}$ & 1.6 & & 9.0 & W402X/W402X \\
10 & $\mathrm{M}$ & 0.9 & & 6.3 & $? / ?$ \\
\hline
\end{tabular}

* If applicable.

$?=$ Unknown mutation.

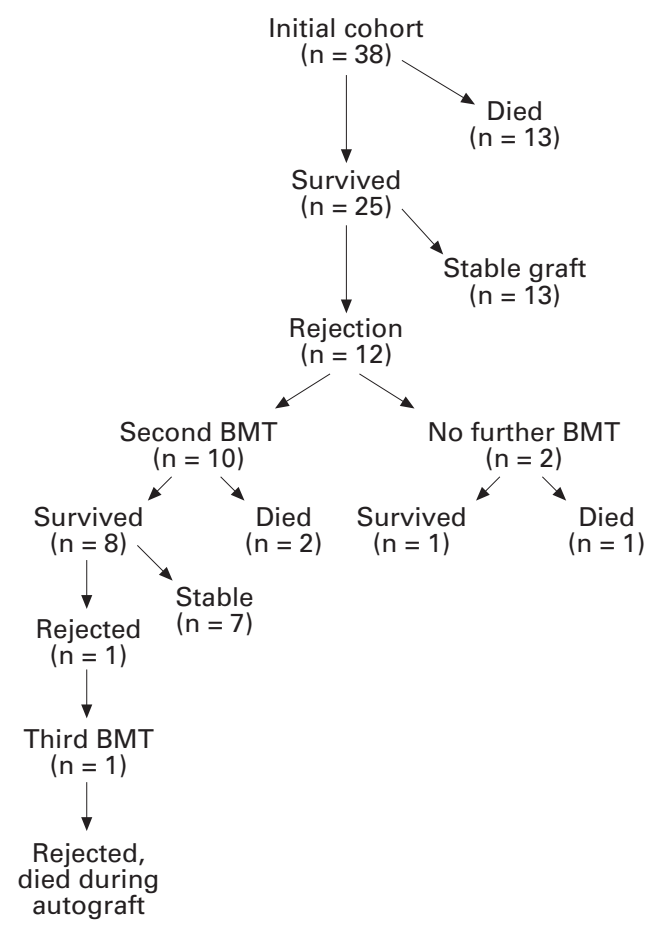

Figure 1 History of the original cohort.

LEUCOCYTE $\alpha$-L-IDURONIDASE ACTIVITY

Leucocyte $\alpha$-L-iduronidase activity was measured using 4-methylumbelliferyl- $\alpha$-L-iduronide essentially as described by Young for chorionic villi. $^{15}$

URINARY GAGS

Total urinary GAG excretion, electrophoresis, and quantitation of the individual GAG components in urine were determined as described by Whiteman and Young. ${ }^{16}$

\section{Results}

There were 13 deaths after the first transplant. Nine occurred in the early post-transplant period (<100 days) of infectious complications or graft-versus-host disease. Of the 25 patients who survived the first transplant, 12 underwent autologous reconstitution or developed partial chimerism and eventually rejected their graft. Ten of these patients underwent a second transplant and eight survived. Seven patients have survived with stable engraftment. One patient underwent a third transplant, and rejected it. She died during an attempted autologous rescue. Figure 1 illustrates the history of the original cohort. There were 17 deaths in all; 12 before 1987 . The mortality was therefore greatest during the early years. It is difficult to compare such a small heterogenous series with BMT for other disorders. However, two points can perhaps be made. First, the majority of deaths resulted from nonHLA identical transplants, as might be expected. Second, there were, surprisingly, no deaths from cardiac causes. The causes of death are shown in table 3.

Twenty one patients have survived from 22 days to 15 years post-BMT. All survivors were censored at 15 September 1995. Of these, 13 have survived for longer than five years. Two 


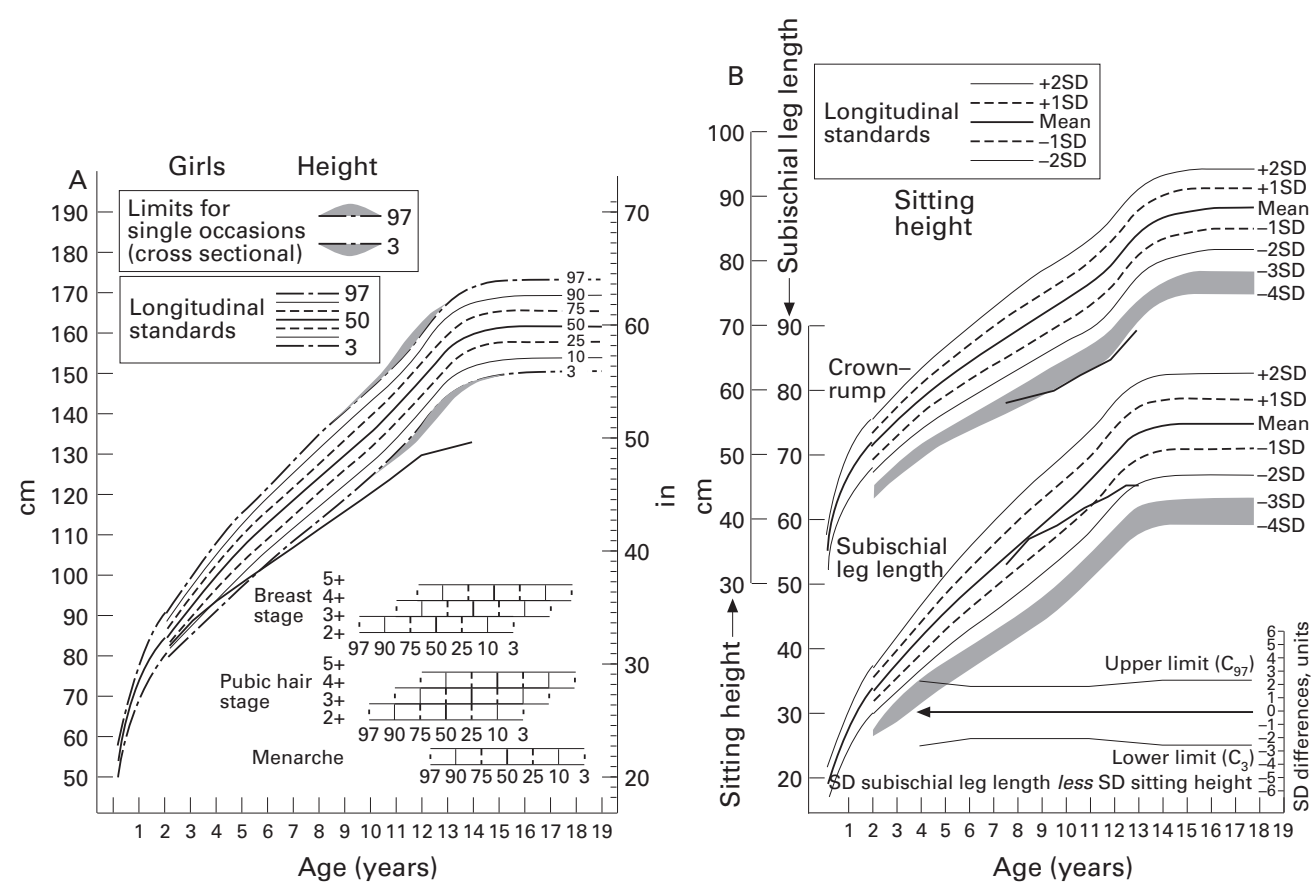

Figure 2 Linear growth chart showing gradual falling off of height $(A)$ and sitting height and subischial leg length: note the relative position of the latter $(B)$.

patients are being followed up elsewhere, and one failed to engraft. Ten patients were therefore available for assessment of long term outcome, from five to 15 years post-BMT, and retrospective correlation of genotype (table 4).

GROWTH AND DEVELOPMENT

Linear growth

In most patients, linear growth has been maintained for some years, and then has gradually fallen away from the 50 th centile (fig $2 \mathrm{~A}$ ). This is accounted for almost exclusively by the sitting height, reflecting poor spinal growth (fig 2B). The presence of spinal deformity in some of the older patients has, however, rendered precise measurement difficult.

\section{Head circumference}

At the time of BMT, macrocephaly was observed in all except two patients. Post-BMT, there was a slowing down or arrest of growth in all cases (fig 3, pattern A), and the head circumference has returned to normal in two patients. In the others, while it remains enlarged, the disparity is considerably less. This is mirrored by changes in computed tomography of the brain. Eight patients showed ventricular dilatation and communicating hydrocephalus before BMT. Four have had scans between 10 and 12 years after transplant, and all have shown improvement, though not complete resolution. Patient 3 had a normal head circumference before transplant in the presence of hydrocephalus. Ten years after transplant, this had resolved considerably, leaving the patient microcephalic (fig 3, pattern B). Significantly, the transplant was performed at the age of 2.3 years.

Sexual development

Of the five patients who are of pubertal age, two have been investigated for delayed puberty

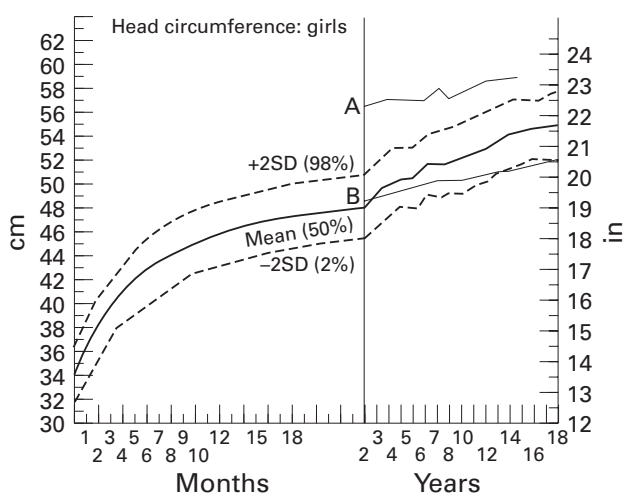

Figure 3 Head circumference after BMT. Pattern A shows the usual response and pattern $B$ refers specifically to patient 3.

and been found to have primary ovarian failure, presumably related to chemotherapy. One patient has sexual infantilism. The other two are thought clinically to be developing normally, although they have not been fully investigated.

PSYCHOLOGICAL ASSESSMENT

Table 2 lists the results of before BMT and most recent psychometric evaluation. Before BMT, one child (patient 5) had a corrected GQ in the average range, that is at or above 85, two (patients 3 and 10) had corrected GQs in the borderline range, that is 70-79, and the remaining seven had corrected GQs in the learning difficulties range, that is below 70 .

After BMT, patient 2 has shown significant improvement (that is by $>1 S D$ ) in intellectual functioning. There was no change in patients 1 , $4,7,8$, and 9 , and there was significant initial deterioration (>1SD) in patients $3,5,6$, and 10. Of these, patients 3,5 , and 6 have shown stabilisation for the last 5-7 years. 
Six out of 10 children, therefore, showed either no deterioration or improved. These results are similar, in many ways, to those reported by Whitley et al. ${ }^{17}$ In their sample of nine surviving children, seven remained stable, albeit with a shorter duration of follow up, and two showed a significant decline.

All the patients except patient 2 have special educational needs. Two (patients 2 and 8 ) attend normal school, one (patient 5) attends a school for physically handicapped children, and six (patients 3, 4, 6, 7, 9, and 10) are at schools for children with learning difficulties. Patient 1 has left school, having taken his final examinations, and attends a special course for disabled school leavers.

Specific problems encountered were:

(1) Severe overactivity/impulsivity. This prevents optimal cooperation, which may be reflected in underestimation of the patient's true level of mental ability. It could reflect early central nervous system damage, which might be prevented by early diagnosis and BMT.
(2) Motor difficulties, which are reflected in lowered scores on the locomotor and eye-hand coordination subscales of the GDMS.

(3) Hearing and speech impairment, related to middle ear effusion.

\section{EXTERNAL CHARACTERISTICS}

Facies

The facial features have been considerably modified, being noticeably less coarse. The mid-facial hypoplasia characteristic of the untreated condition is seen, but is less striking. It is more discernible in some patients than others (fig 4).

\section{Corneal clouding}

There has been a noticeable improvement in corneal clouding in most patients. Two have experienced complete clearing. Patient 4 has had a corneal transplant (see below).

\section{MUSCULOSKELETAL}

Pretransplant, radiography revealed typical features of dysostosis multiplex in all patients. ${ }^{18}$ All 10 patients remained mobile for approxi-
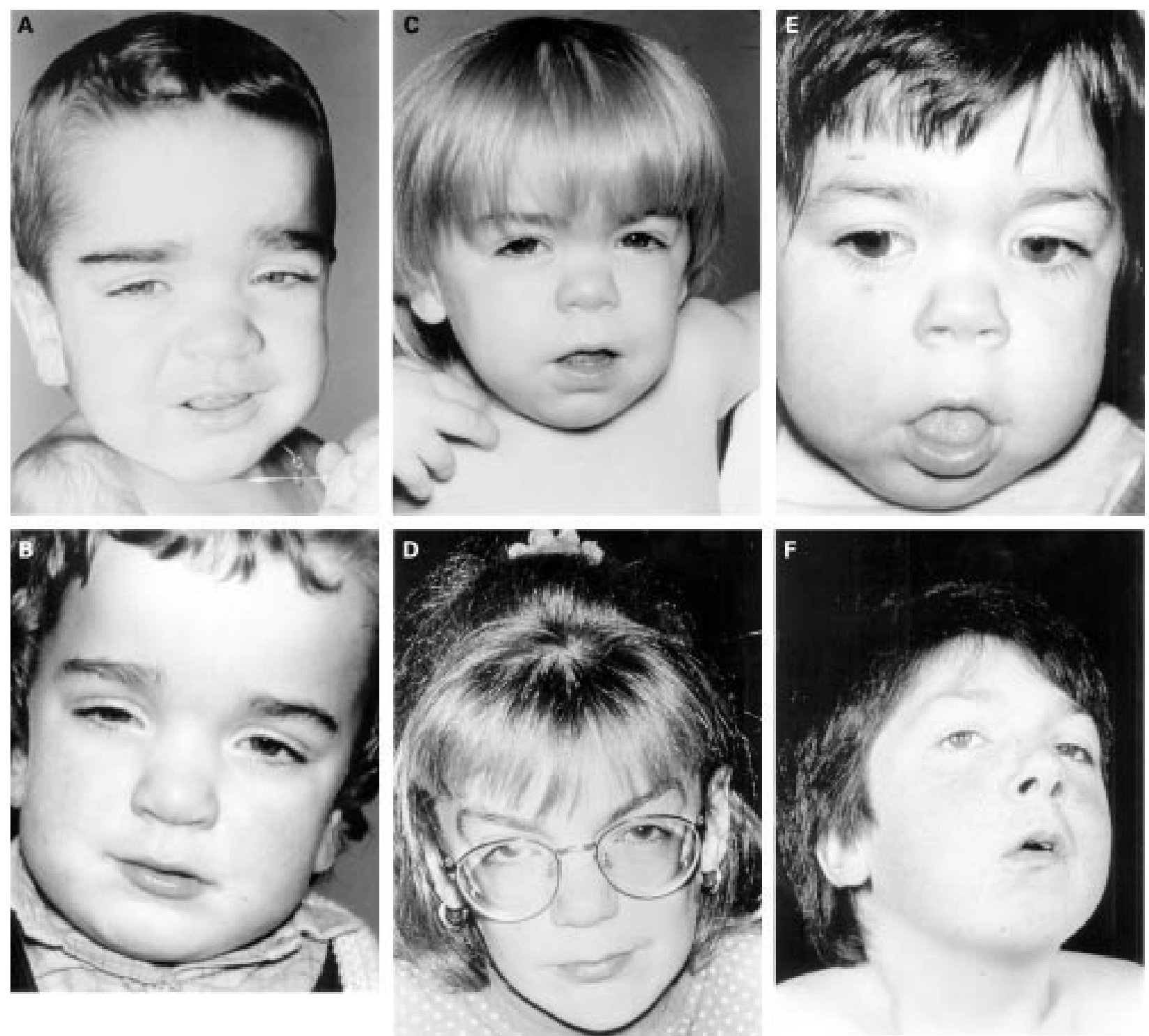

Figure 4 Facial features before $(A, C, E)$ and after $(B, D, F) B M T$ showing considerable variation in the rate of resolution. 

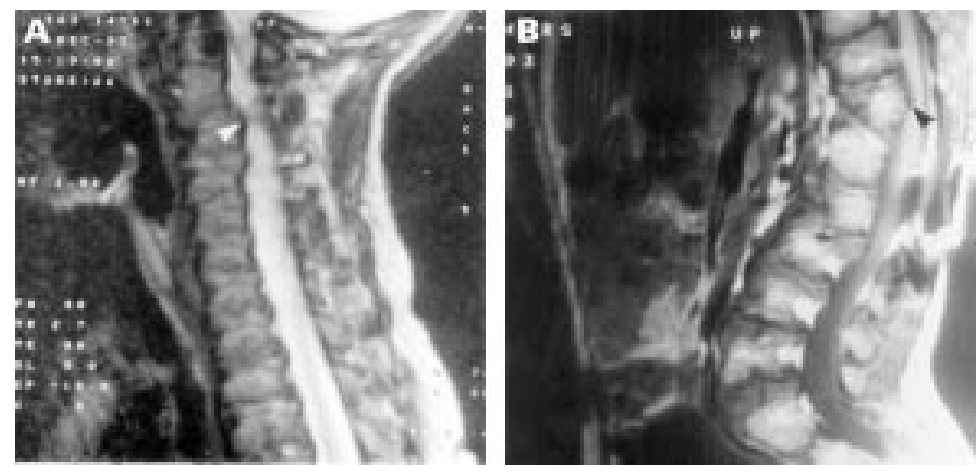

Figure 5 MRI scans of the spinal cord, 12 years after BMT, showing (arrowheads) cervical subluxation and cord compression (A) and thoracolumbar compression (B).

mately 5-6 years after BMT, after which most then began to 'slow down' with increasing pain and stiffness of the hips and knees and spinal curvature. Morning stiffness is particularly common. Radiologically, two characteristics are seen: (1) failure of endochondral ossification and (2) development of osteoarthritic changes, particularly noticeable in the hips, and associated with subluxation in several patients. Magnetic resonance imaging (MRI) of the knees in one patient revealed displacement of the menisci and absence of the tibial notch. Most patients report symptomatic relief with standard anti-inflammatory drugs. Two patients are now completely wheelchair dependent, three are able to walk unaided for short distances only, and the other five are mobile. Femoral osteotomies were performed in three of the younger patients in the hope that the acetabulum would remodel. As this has failed to happen, it was felt that an acetabular reconstruction might be more appropriate. However, none of the 10 long term patients has had an acetabular reconstruction (an 11th patient has, but it is too early to say how successful it has been).

Carpal tunnel syndrome has been seen in seven patients. After decompression, nerve conduction velocities improved in six, but did not return to normal. Of the six who improved, carpal tunnel syndrome recurred in one. MRI of the wrist revealed median nerve compression. After a second decompression, there was still no improvement in the nerve conduction velocity.

SPINAL

All patients have had MRI scans of the spinal cord. All have shown an increase in soft tissue anterior to the dens (odontoid process). Other findings are odontoid hypoplasia (three patients), ligamentous thickening (four), and canal stenosis (four). One patient had cervical instability as seen on plain films. Four patients showed evidence of cord compression at cervical (one), thoracolumbar (two), or both (one) levels. The thoracolumbar kyphosis progressed in all cases. Six patients have had prophylactic posterior spinal fusion performed at an average age of 91 months (45-124); this proved useful in slowing down progression. One patient (number 1) required an occipitocervical fusion and thoracolumbar decompression for cervical instability and cord compression (fig 5). A sec- ond patient (number 5) required a thoracolumbar decompression and fusion for cord compression (this patient had not had a prophylactic fusion). It is clear that these patients have significant spinal cord pathology, which may be responsible for the loss of mobility in some of them.

\section{VISION}

None of the patients has normal visual function. Distant vision is affected more than near vision, so that the patients have to sit at the front of the class, or have a special board. Four patients require glasses.

Four patients have had electrophysiological studies. Three showed an abnormal electroretinogram (ERG). The fourth has a normal ERG but the visual evoked potential studies show postretinal dysfunction.

Before BMT, all patients had corneal clouding visible to the naked eye. In two patients, this has resolved completely. In the others, improvement was seen for the first two years, after which no further improvement was seen. In view of persistent corneal clouding and poor vision, three patients have been considered for corneal transplantation. This was thought appropriate in patient 4 , who had an acceptable IQ and good mobility, but whose independence was restricted due to her impaired vision, for example she was unable to cross the road unaided. Postoperatively, her visual acuity has improved, but there is residual amblyopia. Significantly, her ERG is normal, suggesting that an earlier operation might have achieved better results.

\section{HEARING}

Before BMT, all patients had a conductive hearing loss. Grommets were inserted just before transplant, as the middle ear was a potential source of infection. The hearing loss did not resolve immediately; several patients required reinsertion of grommets, the latest being five years after transplant. However, there was a gradual improvement in hearing over the next few years. Currently, four patients have no hearing loss, although in two this is only a subjective impression. Of the other six, three have a mild conductive loss but do not require aids, one has a mixed bilateral hearing loss and another has a bilateral sensorineural loss of 30-40 db, both requiring hearing aids. One patient is untestable.

\section{CARDIAC}

Echocardiograms were available for seven patients before and after BMT. The findings have been reported in detail by Gatzoulis et al. ${ }^{3}$ Only patient 8 , who presented at the age of 6 months with congestive heart failure, had cardiac signs or symptoms before BMT. Her echocardiogram showed a dilated left ventricle with a restrictive defect. After BMT, this has improved. In the other six, the echocardiogram was normal before BMT, and has remained so. The remaining three patients have had echocardiography after but not before BMT. Two have shown valve thickening, one with and one without trivial mitral regurgitation; both 
have normal ventricular function. The third is normal. Currently, no patient has any clinical evidence of cardiomyopathy.

\section{BIOCHEMISTRY}

Leucocyte $a-L$-iduronidase activity

Before BMT, all patients had grossly reduced $\alpha$-L-iduronidase activity, consistent with a diagnosis of MPS-I. After BMT, the enzyme activity has increased and remained either within the range of heterozygotes for MPS-I or within the normal reference range depending on the enzyme activity of the donor.

\section{Urinary GAGs}

After BMT, the urinary GAG electrophoresis pattern has not normalised; dermatan sulphate was found in all patients tested. However, the ratio of dermatan sulphate to chondroitin sulphate is much lower than that found in untreated MPS-I patients.

\section{Molecular genetics}

Four of the patients were homozygous for the W402X mutation. Two were compound heterozygotes for the W402X and Q70X mutations. One patient (number 8 ) was a compound heterozygote for the W402X and an as yet undefined mutation. Patient 2 was homozygous for the A75T mutation. The W402X, Q70X, P533R, R89Q, L218P, A327P and $\mathrm{A} 75 \mathrm{~T}$ mutations have all been excluded in patient 10 .

\section{Discussion}

It is clear that BMT in patients with MPS-I corrects the enzyme defect in white blood cells, but does not achieve clinical correction. The natural history of the disease is modified, and the fatal complications prevented, so that life expectancy is prolonged. We are therefore seeing new clinical problems. Unfortunately, the lack of control data for some of our findings (for example MRI) limits assessment of our patients after BMT.

Initially there was concern as to whether the relevant enzyme was expressed in the central nervous system after BMT. Direct evidence of this is seen in various animal models of lysosomal storage disorders, including dogs with $\alpha$-L-iduronidase deficiency, ${ }^{19-21}$ but there is no direct evidence in man. However, the slowing down and, in some cases, arrest, of the anticipated psychomotor retardation, together with the improvement in the appearances on computed tomography, provide good indirect evidence. Cells of donor origin have been demonstrated in the brain after BMT in humans, ${ }^{22}$ and it is assumed that they express enzyme activity. The precise mechanism of enzyme transfer, however, remains uncertain.

The musculoskeletal problems remain the main concern. Our impression is that they are less severe than in untreated patients, as was the case in the canine model. ${ }^{23}$ However, there is no definite proof of this. Endochondral ossification remains poor. In dogs with MPS-I that have been transplanted, the femoral head cartilage shows two cell populations at necropsy. The cells closest to the articular surface show
'Hurler-like' characteristics, being distended with GAG, whereas those lying deeper are virtually normal. This suggests that enzyme access to cartilage is poor. We have observed the same in costochondral cartilage in a patient dying 18 months after BMT (unpublished data). The reasons for this remain obscure, but are clearly related to abnormalities of cartilage and bone metabolism. Further research to address this issue is required. Spinal problems should be actively looked for, as early treatment is likely to maintain mobility for longer.

Genotyping may be useful in interpreting the results of BMT in patients for whom the genotype/phenotype correlation is known. Most of our patients have been shown to be homozygotes or compound heterozygotes for alleles associated with the severe form of the disease. It is clear, therefore that BMT has modified the natural history of the condition. There is, however, considerable variation even within the same genotype, leading us to believe that there may be unknown 'modifier' genes. It will also undoubtedly be a valuable tool for patient selection in future, when such analysis becomes automated and more quickly available. At present, its use in selection is limited, as in the case of patient 2. This patient was homozygous for the A75T mutation. No untreated patients with this genotype have been described. Residual protein activity may provide additional information in such cases. In patient 2 , the small amount of $\alpha$-Liduronidase protein detected, with a $K_{m}$ slightly above normal, is consistent with a prediction of a less severe phenotype. ${ }^{8}$

The optimal age for BMT in terms of intellectual outcome will, perhaps, remain uncertain until larger numbers have been transplanted. None of the patients transplanted above the age of 2 are functioning at an acceptable intellectual level. Therefore we would not recommend a transplant above this age. We would caution against the use of IQ $<80$ as a contraindication to BMT, as suggested by Whitley et al. ${ }^{17}$ Nine of our patients had a 'corrected' IQ/GQ of $<80$ before BMT, and their outcomes have varied considerably. Even though different assessment techniques were used by Whitley et al and ourselves, a low score may be misleading, as can be seen from patient 2. Young children can be particularly difficult to assess. Hydrocephalus accompanied by an enlarged head circumference is not a contraindication. However, hydrocephalus in the presence of a normal head circumference may be associated with a poor intellectual outcome (patient 3), although larger numbers of patients are required to verify this.

Second transplants should not be carried out automatically. The patient should be reassessed critically.

The choice of donor, that is whether to use a donor with a normal enzyme level or a heterozygote, is a matter for debate. Transplantation from a donor with a normal enzyme level is theoretically preferable. However, in our view the numbers are too small to draw any definite conclusions. Therefore, if a matched sibling heterozygote donor is available, there is, at 
present, no justification in looking for an unrelated donor, in view of the risks involved.

Quality of life is an important consideration, as it is clear that this is affected. No objective studies have been carried out so far. Good paediatric models of quality of life are urgently required.

In conclusion, we feel that BMT for MPS-I should now be considered a therapeutic modality in selected patients. We would recommend that such transplants be carried out only in centres with appropriate paediatric metabolic expertise. The experience gained from treating these patients has important implications for somatic gene therapy, using bone marrow stem or derived cells as the vehicle, because the mechanism is the same.

The work was carried out at the Westminster Children's Hospital, the Royal Manchester Children's Hospital, the Institute of Child Health, and Great Ormond Street Hospital Trust.

CM was part funded by the Society for Mucopolysaccharide Diseases. We are grateful to Dr D Fabry for her valuable assistance with the psychological assessments, the medical and nursing staff on Gomer Berry ward, Westminster Children's Hospital and the COGENT Trust. Mr J Rainer, Enzyme Unit, tal and the COGENT Trust. Mr J Rainer, Enzyme Unit, Laboratory, performed most of the urinary GAG and leucocyte enzyme assays.

1 Neufeld EF, Muenzer J. The mucopolysaccharidoses. In: Scriver CR, Beaudet AL, Sly WS, Valle D, eds. The Scriver CR, Beaudet AL, Sly WS, Valle D, eds. The
metabolic and molecular basis of inherited disease. 7 th Ed. New metabolic and molecular basis of inherited

2 Hobbs JR, Hugh-Jones K, Barratt AJ, et al. Reversal of clinical features of Hurler's disease and biochemical improvement after treatment by bone marrow transplantation. Lancet 1981;ii: $709-12$

3 Gatzoulis MA, Vellodi A, Redington AN. Cardiac involvement in mucopolysaccharidoses: effects of allogeneic bone marrow transplantation. Arch Dis Child 1995;73:259-60.

4 Field RE, Buchanan JAF, Copplemans MGJ, Aichroth PM. Bone marrow transplantation in Hurler's syndrome: effect on skeletal development. $\mathcal{F}$ Bone foint Surg Br 1994;76:97581.

5 Fuggle PW, Tokar S, Grant DB, Smith I. Rising scores in British children: recent evidence. $\mathcal{F}$ Child Psychol Psychiatry 1992;33:1241-7.

6 Wechsler D. Wechsler intelligence scale for children. 3rd Ed UK. Sidcup, Kent: Psychological Corporation Ltd, 1992.

7 Scott HS, Bunge S, Gal A, Clarke LA, Morris CP, Hopwood JJ. Molecular genetics of mucopolysaccharidosis type 1 : diagnostic, clinical, and biological implications. Hum Mutat 1995;6:288-302.

8 Hopwood JJ, Vellodi A, Scott HS, et al. Long-term clinical progress in bone marrow transplanted mucopolysaccharidosis type I patients with a defined genotype. I Inherit Metab Dis 1993;16:1024-33.

9 Miller SA, Dykes DD, Poleski HF. A simple salting-out procedure for extracting DNA from human nucleated cells. Nucl Acid Res 1988;16:1215.

10 Moscowitz SM, Phuong TT, Neufeld EF. Mutation in Scheie syndrome (MPS IS): a G-A transition creates a new splice site in intron 5 of one IDUA allele. Hum Mutat 1993;2:141-4.

11 Clarke LA, Nelson PV, Warrington CL, Morris CP, Hopwood JJ, Scott HS. Mutation analysis of 19 North American mucopolysaccharidosis type I patients: identification of two additional frequent mutations. Hum Mutat 1994;3:275-82.

12 Boerwinkle E, Xiong W, Fourest E, Chan L. Rapid typing of tandemly repeated hypervariable loci by the polymerase chain reaction: application to the apolipoprotein B 3' hypervariable region. Proc Natl Acad Sci U S A 1989;86: 212-6.

13 Kasai K, Nakamura Y, White R. Amplification of a variable number of tandem repeats (VNTR) locus (pMCT118) by the polymerase chain reaction (PCR) and its application to forensic science. F Forensic Sci 1990;35:1196-200.

14 Priestley L, Kumar D, Sykes B. Amplification of the COL2A1 3' variable region used for segregation analysis in COL2A1 3' variable region used for segregation analysis in 525-6.

15 Young E. Prenatal diagnosis of Hurler disease by analysis of alpha-iduronidase in chorionic villi. $\mathcal{F}$ Inherit Metab Dis 1992;15:224-30.

16 Whiteman P, Young E. The laboratory diagnosis of Sanfilippo disease. Clin Chim Acta 1977;76:139-47.

17 Whitley CB, Belani KG, Chang P-N, et al. Long-term outcome of Hurler syndrome following bone marrow transplantation. Am f Med Genet 1993;46:209-18.

18 Spranger J. The systemic mucopolysaccharidoses. Ergebnisseder Inneren Medizin und Kinderheilkunde 1972;32:165.

19 Shull RM, Breider MA, Constantopoulos GC. Long-term neurological effects of bone marrow transplantation in a canine lysosomal storage disease. Pediatr Res 1988;24:34752 .

20 Hoogerbrugge PM, Suzuki K, Poorthuis BJHM, Kobayashi $T$, Wagemaker G, van Bekkum DW. Donor-derived cells in the central nervous system of twitcher mice after bone marrow transplantation. Science 1988;239:1035-8.

21 Walkley SU, Thrall MA, Dobrenis K, et al. Bone marrow transplantation corrects the enzyme defect in neurons of the central nervous system in a lysosomal storage disease. Proc Natl Acad Sci U S A 1994;91:2970-4.

22 Unger ER, Sung JH, Manivel JC, Chenggis ML, Blazar BR, Krivit W. Male donor-derived cells in the brains of female sex-mismatched bone marrow transplant recipients: a Y-chromosome specific in situ hybridization study. $\mathfrak{f}$ Neuropathol Exp Neurol 1993;51:460-70.

23 Breider MA, Shull RM, Constantopoulos GC. Long-term effects of bone marrow transplantation in dogs with mucoeffects of bone marrow transplantation in dogs with
polysaccharidosis I. Am $\mathcal{F}$ Pathol 1989;134:677-92. 